Document downloaded from:

http://hdl.handle.net/10251/70780

This paper must be cited as:

Cantó Perelló, J.; Jorge Curiel-Esparza (2013). Assessing governance issues of urban utility tunnels. Tunnelling and Underground Space Technology. 33:82-87.

doi:10.1016/j.tust.2012.08.007.

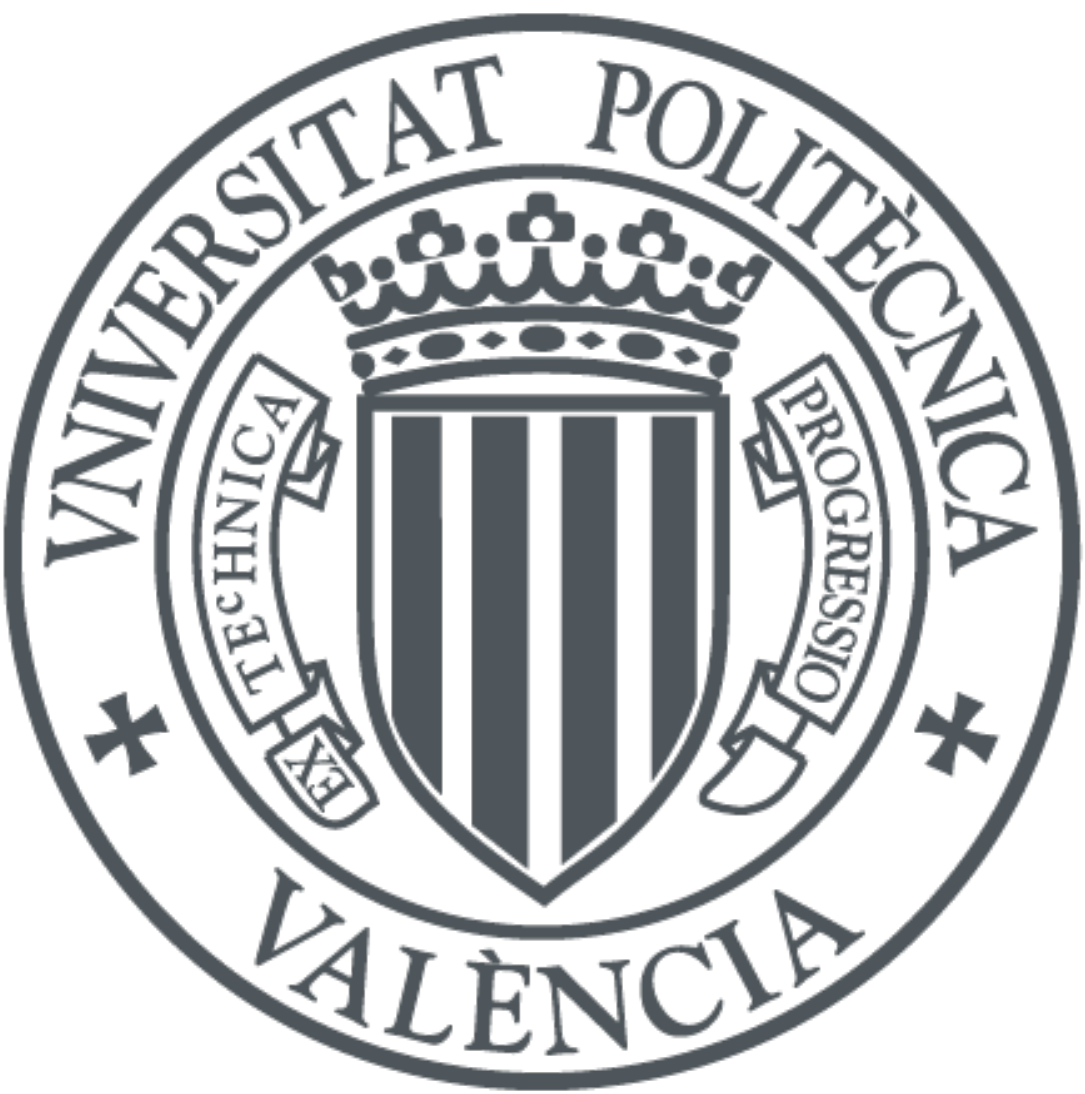

The final publication is available at

http://dx.doi.org/10.1016/j.tust.2012.08.007

Copyright Elsevier

Additional Information 


\title{
ASSESSING GOVERNANCE ISSUES OF URBAN UTILITY TUNNELS
}

\author{
Julian Canto-Perello ${ }^{1}$, Jorge Curiel-Esparza ${ }^{2}$ \\ ${ }^{1}$ Departamento de Ingenieria de la Construccion y Proyectos de Ingenieria Civil

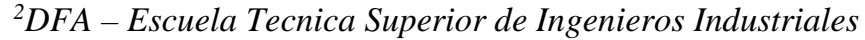 \\ Universitat Politecnica de Valencia, Camino de Vera, s/n, 46022 Valencia, Spain \\ E-mail: ${ }^{1}$ jcantope@cst.upv.es, ${ }^{2}$ jcuriel@upv.es
}

\begin{abstract}
Throughout the centuries, utilities have been an important and sometimes decisive instrument in human development. Municipal policy-makers and engineers have been playing a key role in improving management and technology of urban utilities. With the growth of urban areas and the corresponding increased demand for utility services, available underground space will continue to diminish. Therefore, planning for an urban subsurface sustainable future consists of the ability to lessen the use of traditional trenching techniques and developing coordinated installations of utilities. As an innovative problem-solving technique, utility tunnels become inevitable to reduce congestion of the shallow underground. Utilities management becomes more complex as many public authorities and private companies are involved. Because of the complexity of ownership of the various utility tunnel potential occupants, some form of governmental ownership would probably be the most practicable, although other forms (individual private, joint private, or condominium) of ownership must be analysed. Whatever the form of financing and ownership, some single entity must be made responsible not only for initial construction but also for security, access control, and operation and maintenance throughout the life of the project. The purpose of this paper is to point out some of the utility tunnels innovation and organizational advantages to encourage municipal engineers to demand sustainable solutions for services congestion. Proper adequate governance and security management should be key elements of every decision undertaken in utility tunnels.
\end{abstract}

Keywords: utility services management, utility tunnels security, utility tunnels governance, sustainable underground planning

\section{Introduction}

Today, nearly all urban utilities are buried underground. The transfer from the surface toward underground burial was historically made without real planning: the principal goal was to rapidly solve a problem on the ground by moving it underground in the best technical and financial conditions. However, this approach illustrates a lack of long-term governance of underground space, inhibiting harmonious development of the third dimension (Parriaux et al., 2002). As a consequence, all the urban underground space beneath the pavement level is densely filled with urban utilities in our cities. This mesh of cables and pipelines has been ironically termed "the spaghetti subsurface problem". Modern society cannot live without statutory services, and their number is growing. For this reason, the use of underground space for utilities is by far the most extensive use of the urban subsurface (Carmody and Sterling, 1993; Duffaut, 1996). The definition of sustainable development prepared by the World Commission on Environment and Development, quoted from the report Our Common Future (Brundtland, 1987), reads: 'Sustainable development is development that meets the needs of the present without compromising the ability of future generations to meet their own needs'. Studies carried out by the United Nations on sustainable development have been focused on the global economy, but they could also be applied to utility networks. Society is not sustainable without a proper infrastructure planning (Berner, 2002; Hunt and Rogers, 2005; Wang, 2008). Efforts to achieve sustainability must include innovation to all types of infrastructure including underground (Thibault et al., 2003; Zevgolis et al., 2004; Zhang, 2009). Planning for an urban subsurface sustainable future consists of the ability to lessen the use of traditional trenching techniques. Unfortunately, the general lack of attention to sustainable subsurface options within civil engineers is a factor contributing to street cutting for repairs or installation of new lines and services. Examples of these alternates are:

- Common trench, where several utilities are grouped in a multi-layer single trench.

- Common conduit, where one or more utilities are placed in multiple ducts in a single trench.

- Utility tunnel, which is an underground utilidor containing one or more utility systems, permitting the installation, maintenance, and removal of the system without making street cuts or excavations. 
As an innovative sustainable problem-solving technique, utility tunnel networks are increasing to reduce congestion of the shallow underground (Curiel-Esparza et al., 2004). These systems are capable of integrating urban utilities in an easily accessible space at any point of their length. Use of utility tunnels dates back to the engineers of the Roman Empire, who place water supply conduits in the sewerage systems. An example of this technology can be found in the sewers of Rome, with a huge cross-section that is still in use. These underground facilities were forgotten during the Middle Ages, but were resurrected in 1855, when Haussman's project for reforming the urban utility systems of Paris was approved (Engineering News, 1907). The London facilities date from 1861, when a new street was opened from Covent Garden Market to St. Martin's Lane, having a central arched passageway beneath it with branches for the various house connections from the water, gas and telegraph mains (Engineering News, 1900). In Spain, municipal engineers have been arguing for integrated tunnels since 1867, when Ildefonso Cerda wrote his work "Teoria General de la Urbanización, y aplicacion de sus principios y doctrinas a la Reforma y Ensanche de Barcelona” (Cerda, 1867). But the days of the all-powerful municipal engineer have ended. Nowadays, the lack of coordination is increasing by the large range of public authorities and companies who are separately responsible for urban underground utilities. The purpose of this paper is to point out some of the utility tunnels engineering and management advantages and disadvantages to encourage municipal engineers to demand sustainable solutions for utilities congestion. First, a survey of these underground facilities must be conducted taking into account that utility tunnels are man-accessible. The temptation to provide space for utilities without regard to human factors in terms of safety and accessibility must be avoided. Risk analysis is essential for rational strategic technology management in subsurface facilities. Moreover, the governance of a utility tunnel is a synergistic undertaking, and any legal arrangements or agreements relating to there will be complex. Past experience is deemed to be helpful to this discussion. Legal aspects and financial considerations are also important factors to be considered in establishing and maintaining urban underground sustainability. Of equal or greater concern is the issue of tunnel security. By placing all of the utilities in a common tunnel, utility companies are placing all their "eggs in one basket". In response to the events of September 11, governmental authorities have been stepping up security efforts in these underground facilities. Security considerations must be included in utility tunnel planning and operation.

\section{Utility tunnel practice in urban areas}

Most comprehensive utility tunnel networks are located in city centres where traffic congestion is critical, utilities are dense, and the total cost of utility cuts and traffic interference is great. Other utilidors have been concentrated in the areas of university campuses, hospitals, building complexes, airports, nuclear power plants and industrial facilities. This is consistent with the first motivation for utility tunnels in the past, the elimination of utility cuts and the resulting traffic congestion, improving environmental sustainability and aesthetic community appearances (Canto-Perello and Curiel-Esparza, 2006). However, the success of utility tunnels in many cities, like Madrid and Barcelona, has encouraged officials to extend these underground facilities to where it now is found throughout the city, although they are normally located along the main arteries. Reduction or elimination of street cutting for repairs (a huge advantage in inner city areas), new lines and services, the associated problems of traffic congestion, noise and damage to other utilities are still prime pros to use utilidors. The excavations not only are a prime cause of traffic delay and congestion but also affect the urban street structure, requiring additional pavement maintenance and earlier than normal reconstruction. When a utility tunnel system is properly planned, future service connections can be made with minimum or no excavation, and system expansion is easier compared to conventional underground utility practice.

The main problems causing interruption to service associated with an urban underground utility are related to corrosion and damage to the cables by other utilities and contractors. In addition, utility tunnel security is matter of great concern, particularly since the 9/11 terrorist attacks. Inspection and preventive maintenance of utilities is easier in utility tunnel systems permitting early identification and reduction of potential sabotage or failures, increasing the utility economic life and reducing probability of rupture to pipe-type systems. Moreover, maintenance works can be developed under all climatic conditions with these subsurface facilities, minimizing maintenance and operating costs for some or all utilities as compared to conventional practice. Damage to pipes and cables by others is minimal since blind digging is eliminated. Utility tunnel practice eliminates or reduces to a minimum corrosion problems, which usually appear in buried pipelines (CantoPerello and Curiel-Esparza, 2003). The common types of corrosion that can occur in a buried pipeline are pitting corrosion because of material in-homogeneities and concentration cells in soil arising out of differences in oxygen concentration in the soil adjacent to the pipe at different regions; microbiologically induced corrosion under anaerobic conditions and stray current corrosion by earth return direct currents. Soil 
settlements and top loads are also possible damage factors avoidable using utility tunnels technique. Damage to utility infrastructure is mainly due to the natural aging of the structural materials since utility structures remain in service exceptionally long and to changes in the operating condition. The principal failure hazard to such structure arises from the lack of routine inspections (Madryas, 2008). Therefore utility tunnels increase reliability of services as compared to conventional trenching installation practice, and with adequate measures security risks should be avoided.

The utilidor cross-section must be designed taking in account a space for utilities without regard to employee's space needs in terms of accessibility (see Figure 1). Two space considerations must be done (Canto-Perello and Curiel-Esparza, 2001). In order to fit the confined workplace environment of a utility tunnel to the employee, some design rules should be followed: establishing maximum and minimum distances to project the workplace architecture; placing conduits on shelves to allow workers to maintain vertical torso postures; selecting width and vertical location of shelves for a recommended weight limit; and avoiding the use of utility tunnels as sewer systems. On one hand, the easiness of system expansion as compared to traditional underground utility practice if tunnel system is properly planned. A utility tunnel is designed to transport a known number and type of urban services, and the space reserved for future utilities is a fixed parameter. Utility tunnels should be finely tuned to future demands in space requirements to avoid becoming outdated too early. Well-planned utility tunnels provide expansion, maintenance, inspection and repair of utilities with no excavation. However, the need to provide this expansion space along with the necessary access space produces the main disadvantage of the utility tunnel, that is, the high initial cost. On the other hand, utility tunnels promote a reduction of rights-of-way space requirements. Urban underground space is a finite and non-renewable resource (Cano-Hurtado and Canto-Perello, 1999). The increasing shortage and cost of rights-of-way together with the proliferation of utility services in both type and degree accentuate the need for improved location and placement of utilities in urban streets and highways. There is a growing trend for sustainable joint use of the underground space rights-of-way.

\section{Utility tunnel technique versus traditional trenching}

Compared with other utility burying techniques, utility tunnels are more expensive on a first-cost basis. From an administrative point of view, implementing these underground facilities is retarded most by the upfront investment and management procedures. However, the use of utility tunnels involves special public benefit, the assignment of which may be very difficult. That is to say, the effect of street cuts on traffic flow, maintenance requirements, and street life are also quite difficult to quantify in monetary terms. Excavation is costly because of size and depth requirements, and the need to haul away excess earth (Legrand et al., 2004). In addition, installation and maintenance activities need more coordination as compared to traditional buried systems (Canto-Perello et al., 2009). For safe operation and maintenance, utility tunnels need additional systems like ventilation, lighting, drainage, communication, alarm and escape systems, whose costs should be enclosed in the initial design. Also, utility tunnel good design should include systems like fire detection, suppression, compartmentalisation, means of escape, smoke control and other fire precautions fitted to meet the specific requirements (Abdul Salam, 2007). Moreover, many potential benefits are not easily quantifiable. These include value of time saved in the absence of street cuts, costs in street pavement maintenance and accident reduction. Another problem of utility tunnel systems is the difficulty in addressing the appropriate share of costs to beneficiaries. For all these reasons, it is not feasible to make a general engineering-economic analysis, because each situation will be unique in terms of location, urban population, traffic density, and utilities to be housed, costs of construction and potential customers.

Each subsurface construction has specific identifiable risks. Some of them are obvious, while others can be found in national and international standards. However, for utilidors, a list of characteristic risks is not clearly identified. A serious defect, rupture, or explosion in one system may cause damage and outages to all occupying utilities. Underground facilities are highly complex and difficult to manage; utility tunnels have synergistic characteristics. Synergy denotes the combined and simultaneous action of discrete parts which, taken together, have greater total effects that the sum of their individual parts. This action is essentially not predictable, even given the knowledge of the rules governing the separate parts. The principal risks and potential hazards are: thermal effects resulting from steam and hot water lines on the insulation and carrying capacity of electrical and communication conduits and the temperature of potable water lines; possibility of gas explosion due to leaking gas conduits; potential of electrical and electromagnetic influences from electric power systems; possible danger to other utilities as a result of steam pipe rupture; flooding due to leakage or rupture of water or sewer lines; sewerage systems may also cause unsanitary conditions. 
Site surveys should be undertaken before any maintenance or renovation tasks commence to ensure that risks within an utilidor are identified. Electrical, gas and other possible dangerous utilities should be de-energised whenever possible. If the utilities cannot be de-energised, employees must avoid, or reduce to minimum, contacts with them. Utility tunnels should be inspected periodically to identify safety hazards (Curiel-Esparza and Canto-Perello, 2005). Unsafe conditions detected during inspections should be corrected, and identified hazards should be controlled to prevent future fatalities. Liability is one of the major problems for many companies to share the same space with others. Some companies do not accept the liability that the risk of explosion, flooding and the presence of other company workers in the same space induce. Underground facilities are highly complex and difficult to manage; utility tunnels have "synergistic" characteristics. Synergy denotes the combined and simultaneous action of discrete parts which; taken together, have greater total effects than the sum of their individual parts. This action is essentially not predictable, even given the knowledge of the rules governing the separate parts. Liability of companies differs from one to another; obviously a telephone company's risks are less than a gas. The interference with existing utilities and the interruption of service should be considered in the governance agreements.

\section{Management and financing criteria of utility tunnels}

Throughout the centuries, utilities have been an important and sometimes decisive instrument in human development. The theory that all land and its resources belong ultimately to the people and therefore to the government is very ancient. However, utilities have been privately or publicly owned throughout history. Vitruvius was writing in the first century BC when many of the finest Roman aqueducts were built, and survive to this day, such as those at Segovia and the Pont du Gard. Vitruvius is the author of De architectura, known today as The Ten Books on Architecture (Vitruvius, 1960). The first historical reference to the issue of public or private responsibility in urban commodities appears in this of Vitruvius, as follows: "In the reservoir are three pipes of equal sizes, and so connected that when the water overflows at the extremities, it is discharged into the middle one, in which are placed pipes for the supply of the pools and fountains; in the second those for the supply of the baths, thus affording a yearly revenue to the people; in the third, those for the supply of private houses. This is to be so managed that the water for public use may never be deficient, for that cannot be diverted if the mains from the heads are rightly constructed. I have made this division in order that the rent which is collected from private individuals, who are supplied with water, may be applied by the collectors to the maintenance of the aqueduct”. Urban facilities ownership and management was a public responsibility in the ancient world. In more recent years changes to the political and economic environment and particularly the use of private financing for infrastructure innovation in the developed, transitional and developing economies has resulted in new opportunities and the emergence of new players (Green, 2009).

A major reason for the construction of utility tunnels is to avoid interference with urban transportation networks, both vehicular and pedestrian. Therefore, to minimize interference and disruption, as many utilities as possible should be provided for in the tunnel. In terms of governance this obviously means that both public and private utilities must coexist in the same facility. Assigning management responsibility becomes more complex as many governmental authorities and private companies are involved. The organizational structure must be flexible enough, so that the inability to rather rigidly control the placement of all utilities in a narrow corridor does not cause administrative breakdown, which could require a different organization for each utility tunnel proposed.

Financing the system is a key issue. Placing utility lines in a tunnel approximately doubles the initial capital investment. Based on present research and existing tunnels, one may conclude that forcing all utilities into the tunnel through legislation or by mutual consent is seldom possible or even desirable from the viewpoint of financing. Expectations are that these costs could be recovered in time through reduced utility and street operation and maintenance costs. Formulas need to be developed to apportion the capital costs among the benefiting parties in an equitable manner.

Some of the criteria which financial management of these underground facilities must consider are:

- Use of a utility tunnel can especially benefit commercial and business uses by preventing repeated excavation and traffic interruption for utility construction and repair.

- Benefits of a utility tunnel accrue to the general travelling public in that major streets and roads need not be interrupted. 
- Benefits accrue to the public and private utility companies if the financing required is reduced by assumption of initial capital investment by a governmental agency. The private utility companies should invest in the tunnel only when they choose to use it.

- Property owners other than those abutting the street receive benefits in that the future noise, and the disruption of bypassing and detouring major traffic volumes for a long period may be avoided.

- Government agencies may benefit if the utility tunnel improves coordinated planning for the rightsof-way or the relocation of utilities requires less rigid control of scheduling by companies.

No widely accepted method of assessment has been established to analyse the value of time saved in the absence of street cuts, saving in street maintenance, and the value of lives saved through accident reduction. Moreover, a case study of a utilidor in Barcelona has shown the importance taking into account the value of the underground land used (Riera and Pasqual, 1992). When underground land value is not considered, resources are allocated inefficiently. Many of the benefits of the utilidor concept are not quantifiable in direct monetary terms. Methods for assignment of liability for the tunnels and their operations show obviously an organizational problem. By combining the utilities in one structure the liability problems which may be bad enough when utilities are on the same right-of-way must now include consideration of damage to another utility by the malfunction of an adjacent utility. One of the most complex problems in any joint undertaking for construction or use of any underground facility is the manner of handling any liability which results from the construction, maintenance and operation of the facility. The project effectiveness largely depends on the effective contract preparation. Utility tunnels will be no exception. A final issue relates to time scheduling of construction. Road and street construction is usually planned to be adequate for 20-25 years. The utility companies may use a similar time period for the strategic planning of major new capacity for transmission lines but do not normally provide facilities for distribution for anticipated growth over such a long period. Maintaining and renewing infrastructure for the long term is having significant impacts on the financial sustainability of local government.

\section{Governance arrangements in utility tunnels}

Whatever the form of governance, some single entity must be made responsible for security, access control, operation and maintenance throughout the life of the facility. If public ownership is adopted, the management function would usually fall under the Municipal Public Works Department. It would also be possible to organize a special Utility Tunnels Management Authority. If single private ownership is involved, management could fall within the appropriate department of the utility company. Where two or more private owners are involved, one could be chosen between them by agreement as having management responsibility and authority with the others contributing their fair share of management expenses. The functions of the governance authority, public or private, would include, among others:

1. Obtaining of required permits, easements and coordination with other state and municipal agencies.

2. Planning, project and construction of utility tunnels network.

3. Determination and coordination of criteria for installation and operation of all utility systems to be installed in the utilidor.

4. Operation and maintenance of drainage, lighting, ventilation, fire detection, and gas detection systems.

5. Security and access control procedures.

6. Management of expenses and collection of rates.

Explicit agreements as to the rights and obligations of all concerned will be necessary. Usually, the most important criterion influencing a disputing resolution strategy decision is the financial status (Marzouk et al. 2011). Guarantees of impartial treatment for all users will also be necessary. Private companies must be assured that no preferential treatment will be granted to municipal utilities by a municipal managing agency. The success of any prospective utility tunnel project will depend upon the cooperation and agreement of all participants. If utility tunnels are owned by a single institution, and the same institution also holds title to the land and utilities, agreement is not needed for the project success. Through all phases of planning, financing, construction and operation, the policies and practices of government, public and private utilities and the various regulatory bodies must be considered.

Because of the organizational factors outlined above, there are probably three main organizational arrangements that could be made operational. They are 1) public ownership and jurisdiction (e.g. the city of Madrid); 2) a government supervised but privately controlled utility corporation (e.g.: the city of Barcelona); 3) utility tunnels under utility company or institution ownership (e.g.: universities, hospitals, military 
installations, nuclear plants, etc.). Public ownership appears to offer the widest choice of alternative methods. Such methods include bonding, several types of grant programmes, and combinations. Financial sources available for private ownership are usually limited to conventional financing through issuance of stocks or bonds. Under the public sector management systems are direct municipal ownership and special authorities. Private management systems would include single-private, joint-private and condominium. Whatever the form of management, explicit ordinances, regulations or agreements must be established.

Urban growth needs to be redirected towards meeting the future needs and not just to reduce economic expense to the lowest possible level. Obviously, the initial cost is going to be greater than for traditional trenching. The major advantages of the trenching method are the ability to use specialized machines for rapid excavation and the low cost of this type of excavation. However, in congested areas where large numbers of underground utility lines may already be installed, considerable care must be exercised to ensure continuity of service and prevent damage to these utilities during excavation. Utility tunnels are well-accepted by institutions. In these institutions singular administrative control has literally forced the utilities to join together. One of the greatest obstacles in the development of urban utility tunnel networks is the cooperation and coordination of all government and utility agencies so that a workable plan can be developed. In utility governance, coordination most naturally falls on the municipal agency in charge of the streets. While cooperation with the utility companies is essential, the local government must retain the authority to mediate when a conflict of interest arises. Municipal agencies and utility companies should designate persons from their staffs as utility tunnel coordinators. Their duty is to meet regularly and discuss the immediate as well as long range plans for the underground facility. This liaison eliminates the majority of conflicts that might otherwise arise. A long range plan should project twenty to thirty years into the future and should also be updated at regular intervals to make changes as they become necessary. Utilities planning their own construction can then anticipate when to make necessary changes or additions. It should be emphasized that utility companies should also have some long range plan in effect to compare their needs with those of the governing agency.

\section{Security issues in utility tunnels}

In order to assess physical security and access-control needs, it must be first considered what it is being protected. These considerations include the physical property and the facility operations (Seger 2003). Moreover, when evaluating utility tunnels' threat, it is important to analyse the cascading effect. If utilities are disrupted for a considerable amount of time, there is an impact on many other facilities vital to the community. The utility tunnel owner, itself, or in conjunction with the major utility occupants, should provide for an adequate security system. The responsibility of the parties should be made a part of the agreement. Provisions should be made for guarded entrances. Only authorized personnel should be allowed in the tunnel. Stringent sign-in and sign-out procedures must be implemented and followed carefully. In large tunnels consideration should be given to surveillance by watchmen or use of television or other devices. Not only is it important to spot any in-tunnel trouble immediately, but it is also important to detect and keen nut intruders who may damage or even sabotage the system.

Because of assembly of a large number of utility systems in a small space, the utility tunnel might be an inviting target for vandalism, sabotage or terrorist attacks. In addition, there are groups of people known as urbex (urban explorers) who actively enjoy exploring underground infrastructures and sharing their photographs in internet. The rise in the popularity of urban exploration can be attributed to its increased media attention, numerous newspaper articles and television interviews in the last years. The rule of urban exploring "take nothing but photographs, leave nothing but footprints" may appear without malice, but because of placing information about access to tunnels on anonymous websites, it would be relatively easy for a terrorist or saboteur to enter a facility.

The principal security advantage for underground facilities is that access points are generally limited and easily secured (Sterling and Godard, 2000). All entry points for pedestrians or materials shall be secured, either by locks or mechanical fasteners. Locksets on doors into tunnels shall be locked on exterior at all times, but operable from the interior at any time (no interior keyed locks or deadbolts). Not only entrance doors, but also ventilation openings, entrances to laterals leading to building basements, etc., must be protected. The inclusion of subsurface transportation systems, such as subways, walkways, or vehicular lanes, within utility tunnels is indeed questionable. This adds a severe dynamic force which could be injurious to utility systems as well as violating the security and the controlled atmosphere. Utility tunnels and underground transportation systems should be separated, even if only by a common wall. 
It is also interesting to considerer access-control measures at different threat levels. Access gates and doors that are open during normal operation may be secured at increased threat levels, and non-critical maintenance operations should be postponed. A fire evacuation plan might be used to study the accesses, key assets and how would these be accessed once inside the utility tunnel. The Madrid and Barcelona utility tunnel system is good example of a closely controlled facility. Intercommunication is maintained between all sections and entrances are closely guarded. Access is possible only through control points, and a sign-in, sign-out procedure is rigidly followed. The openings for entrance of materials are operated under similar procedures. Operations and repairs take place in the presence of security officials, and each shift of watchmen make a complete round of the tunnel system under their control, submitting a written report of any irregularities encountered. There have been no reports of serious security incidents, such as sabotage or terrorism.

One of the least expensive countermeasures is protective lighting. In-tunnel lighting should be used at increased threat level or as a result of a suspected intrusion to discourage unauthorized entry. The physical security system of a utility tunnel should include intrusion detection systems, alarm systems and surveillance cameras operating in tandem. Sensors detecting an intrusion should activate an alert at a monitoring centre and notify local police (see Figure 2). Some type of automatic fast acting shutoff device to protect the tunnel and utilities should be installed. All these measures delay the intruder, giving time to police to reach critical areas. There should be an annual inspection and checks of security measures and procedures. Security and access control plans should be proactive.

\section{Conclusions}

The lack of attention to utility tunnels in the urban strategic planning process perpetuates conventional trenching techniques hindering innovation. There is no unsolvable problem connected with the design and organizational management of utility tunnels. Usual engineering technology exists to overcome all potential risks and disadvantages. From a governance point of view, implementing these underground facilities is retarded most by liability factors and organizational structures. Innovation on utility tunnels involves public benefits, the assignment of which is not obvious. Utilidors guarantee the underground space resources for future generations with minimum environmental impact. In any case, this task goes beyond the role of a short-term utilities planning. Sustainability requires a governance capacity for public works strategic planning on a long-term basis.

Because of the complexity of ownership of the various utility tunnel potential occupants, some form of public ownership would probably be the most practicable, although other forms (individual private, joint private, or condominium) of ownership are not ruled out. The authority of local governments makes them ideally suited to assume ultimate responsibility for urban utility tunnel systems. Local government access to numerous sources of capital also provides the ability to raise the large sums of money necessary for major projects benefiting the general public. Should it be deemed desirable and practical, local government also has the power to assign financial responsibility to a project's indirect as well as direct beneficiaries. The lack of this authority would be a serious shortcoming inherent in a private authority responsible for a utility tunnel system.

Utility tunnel security is another matter of great concern. Because of assembly of a large number of utility systems in a small space, the utility tunnel might be an inviting target for vandalism or sabotage. Special administrative and physical precautions would be required to prevent entry by unauthorized persons. Limiting the number of entrances and exits for personnel and material, plus strict sign-in and sign-out procedures offers the sufficient security in existing utility tunnels. Direct entry from buildings served by lateral tunnels should be prevented by bulkheads or suitable locked doors. Closed circuit TV, surveillance and alarm systems might reduce the number of security personnel required, but will not eliminate the need completely. Intrusion detection systems should be used at high-threat locations, but the right system at the right location must be used, otherwise there will be an unacceptable number of nuisance alarms.

Innovation on utility networks need to be aimed towards meeting the future needs, and not just to reduce economic expense to the lowest possible level. Utilities have been located underground in order to achieve less visual impact and more protection against adverse climate, vandalism and natural disasters. Most present subsurface utilities were placed when land was cheap and environmental impacts were not a major factor. The value of the subsurface space has been underrated for a long time. Shallow urban underground space must receive a greater share of attention by policy-makers and engineers. Utility tunnels become significant 
not only for minimising the need to dig up streets for statutory services, but also for the effective use of the valuable underground space under streets. Utility tunnels are one of the most sustainable urban subsurface facilities, and there have been no reports of serious security incidents when appropriate measures have been undertaken. Therefore, they must be included in utility networks planning, even though their governance and security issues might seem discouraging at first sight. The pros of utility tunnels undoubtedly outweigh the cons in a long-term analysis.

\section{References}

Abdul Salam, A.O., 2007. Safety in automated transportation tunnels, in Mediterranean Conference on Control and Automation, MED.

Besner, J., 2002. The sustainable usage of the underground space in metropolitan area, in ACUUS 2002 International Conference Urban Underground Space: a resource for cities.

Brundtland, G.H., 1987. Our common future, Oxford: Oxford University Press.

Cano-Hurtado, J.J., Canto-Perello, J., 1999. Sustainable development of urban underground space for utilities. Tunnelling and Underground Space Technology 14 (3), 335-340.

Canto-Perello, J., Curiel-Esparza, J., 2001. Human factors engineering in utility tunnel design. Tunnelling and Underground Space Technology 16 (3), 211-215.

Canto-Perello, J., Curiel-Esparza, J., 2003. Risks and potential hazards in utility tunnels for urban areas. Proceedings of the Institution of Civil Engineers-Municipal Engineer 156 (1), 51-56.

Canto-Perello, J., Curiel-Esparza, J., 2006. An analysis of utility tunnel viability in urban areas. Civil Engineering and Environmental Systems 23 (1), 11-19.

Canto-Perello, J., Curiel-Esparza, J., Calvo, V., 2009. Analysing utility tunnels and highway networks coordination dilemma. Tunnelling and Underground Space Technology 24 (2), 185-189.

Carmody, J., Sterling, R., 1993. Underground Space Design. New York: Van Nostrand Reinhold.

Cerda, I. 1867. Teoria General de la Urbanizacion, y aplicacion de sus principios y doctrinas a la Reforma y Ensanche de Barcelona. Madrid: Imprenta Espanola.

Curiel-Esparza, J., Canto-Perello, J., Calvo, M.A., 2004. Establishing sustainable strategies in urban underground engineering, Science and Engineering Ethics 10 (3). 523-530.

Curiel-Esparza, J., Canto-Perello, J., 2005. Indoor atmosphere hazard identification in person entry urban utility tunnels. Tunnelling and Underground Space Technology 20 (5), 426-434.

Duffaut, P., 1996. Paris Conference examines the "Rightful Place" of the underground space in the modern city. Tunnelling and Underground Space Technology 11 (1), 126-130.

Engineering, News, 1900. Subways for street pipes and wires. Engineering News and American Journal Railway Journal 43 (11), 176-178.

Engineering News, 1907. Pipe subways in British cities and Paris. Engineering News and American Journal Railway Journal 57 (11), 280-284.

Hunt, D.V.L., Rogers, C.D.F., 2005. Barriers to sustainable infrastructure in urban regeneration. Proceedings of the Institution of Civil Engineers-Engineering Sustainability 158 (2), 67-81.

Green, R., 2009. The essential role of governance in project development. Proceedings of the Institution of Civil Engineers-Municipal Engineer 162 (3), 179-185. 
Legrand, L., Blanpain, O., Buyle-Bodin, F. 2004. Promoting the urban utilities tunnel technique using a decision-making approach. Tunnelling and Underground Space Technology 19 (1), 79-83.

Lemley, J.R., Fthenakis, V.M., Moskowithz, P.D., 2003. Security risk analysis for chemical process facilities. Process Safety Progress 22 (3), 153-162.

Madryas, C., 2008. Forensic investigations of buried utilities failures in Poland. Tunnelling and Underground Space Technology 23 (2), 199-205.

Mazouk, M., El-Mesteckawi L., El-Said M., 2011. Dispute resolution aided tool for construction projects in Egypt. Journal of Civil Engineering and Management 17 (1), 63-71.

Parriaux, A., Tacher, L., Joliquin, P., 2004. The hidden side of cities-towards three-dimensional land planning. Energy and Buildings 36 (4), 335-341.

Riera, P., Pasqual, J., 1992. The importance of urban underground land value in project evaluation: a case study of Barcelona's utility tunnel. Tunnelling and Underground Space Technology 7(3), 243-250.

Seger, K.A., 2003 Utility security: the new paradigm. PennWell, Oklahoma.

Sterling, R.L., Godard, J.P., 2000. Geoengineering Considerations in the Optimum Use of Underground Space, Proc. GeoEngineering 2000, Melbourne, Australia.

Thibault, S., Trépanier, M., Fougères, D., 2003. The urban underground of Montreal: the commission of electrical and public services. Canadian Journal of Urban Research 12 (1), 77-101.

Vitruvius, M., 1960. The Ten Books of Architecture (Traslated by Morris Hicky Morgan). New York: Dover Publications.

Wang, J.H., Koizumi, A., Liu, X., 2008. Advancing sustainable urban development in China. Proceedings of the Institution of Civil Engineers: Municipal Engineer 161 (1), 3-10.

Zhang, J.-C., Ding, X.-M., Pang, Y.-S., Li, W.-P., Tong, H.-W., Zheng, X.-C., Xu, Y., 2009. Analysis for development and utilization of underground space in Guangzhou. Gongcheng Lixue/Engineering Mechanics 26 (S2), 106-114.

Zevgolis, I.E., Mavrikos, A.A., Kaliampakos, D.C., 2004. Construction, storage capacity and economics of an underground warehousing-logistics center in Athens, Greece. Tunnelling and Underground Space Technology 19 (2), 165-173. 


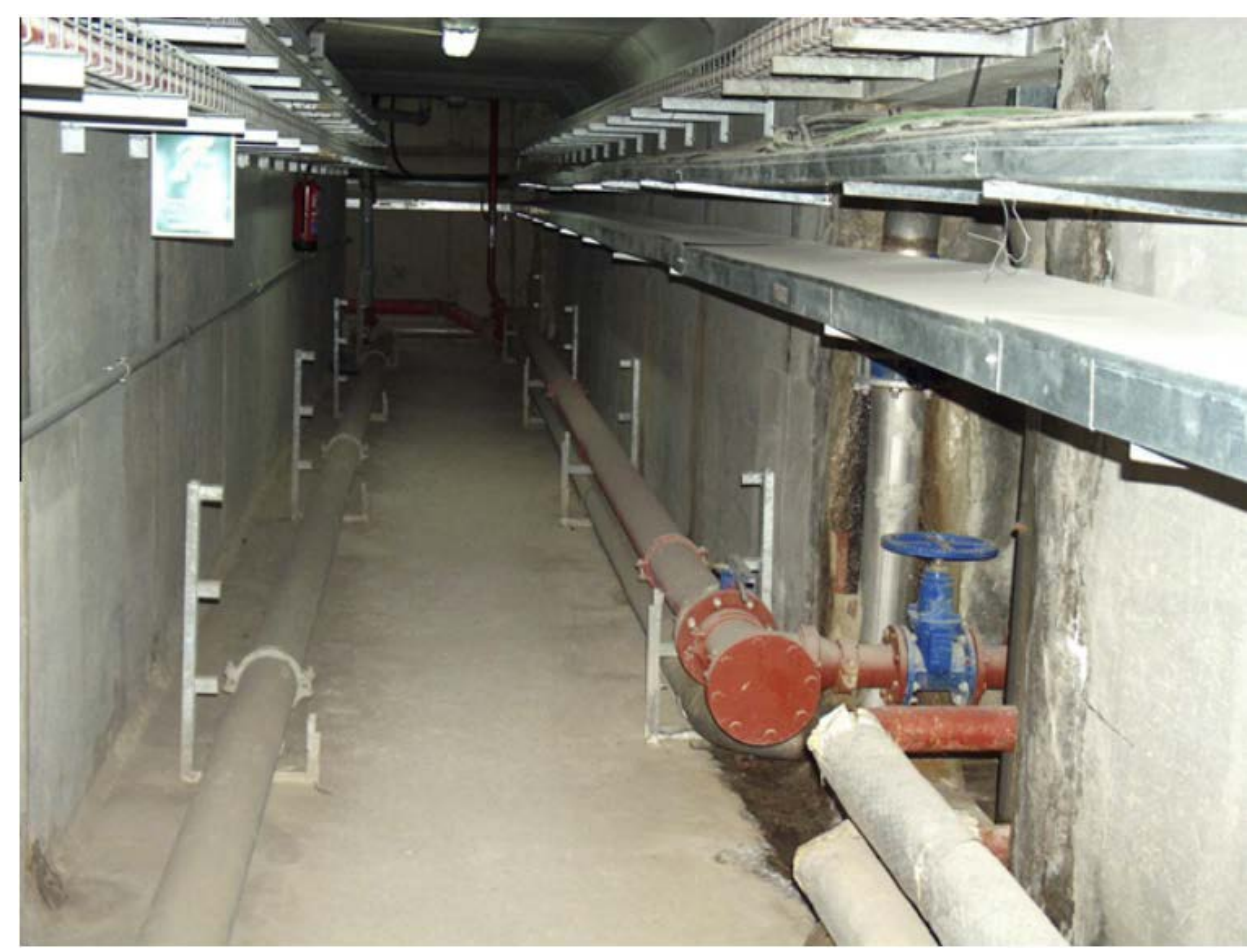

Figure 1. Walk-through utility tunnel cross-section permits the installation, maintenance and removal of utilities without making street cuts or excavations. Pipe and conduit racks are mounted on the utility tunnel walls, improving accessibility and maintainability, and minimising personal injuries.

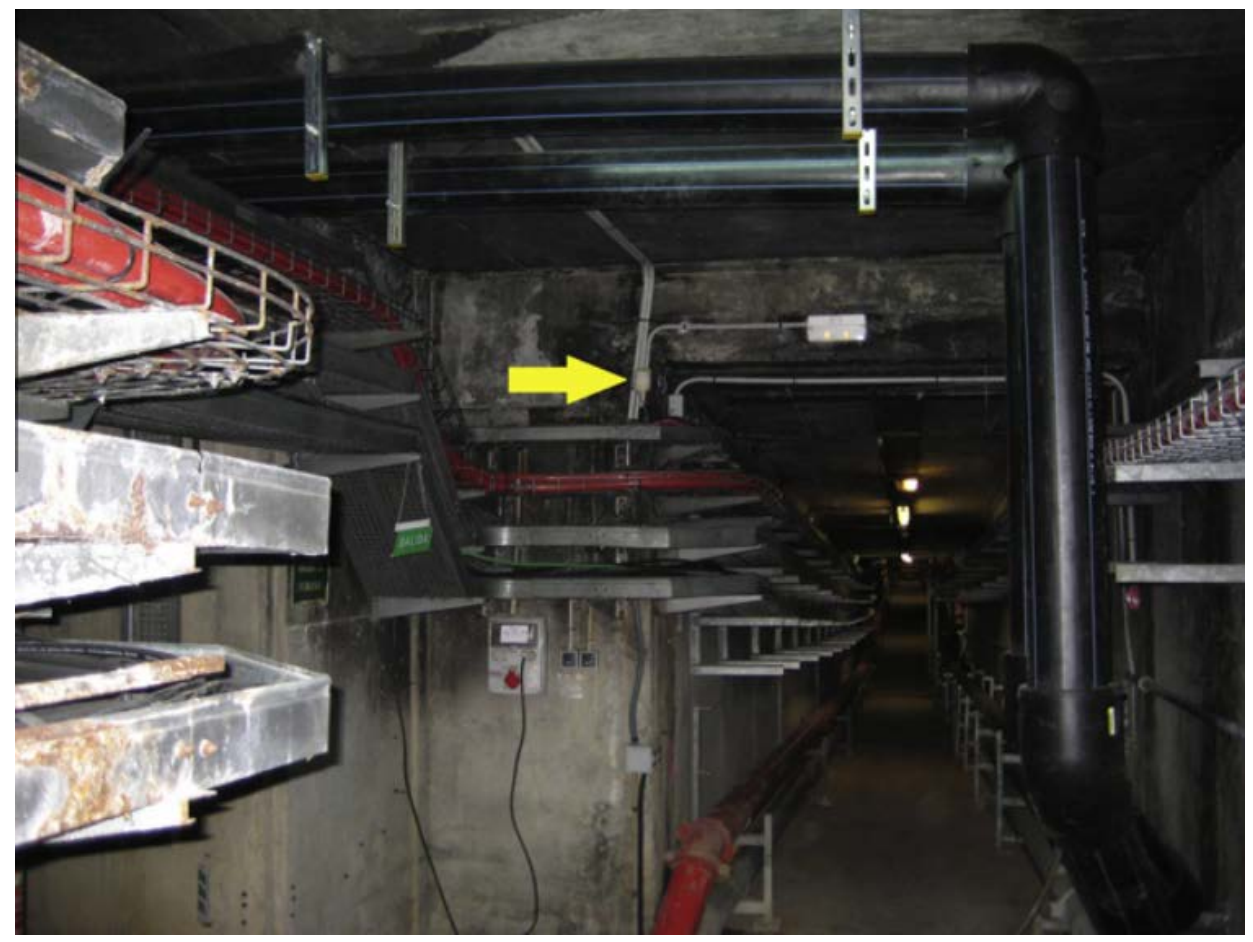

Figure 2. Some sensors are intentionally visible while others are hidden. The petty intruder will be detected by visible sensors, while covert sensors will deal with the professional criminals or terrorist. 